\title{
Thermal cooling analysis of single Li-ion battery cell with elliptic heat sink with perforation
}

\author{
Karim Egab ${ }^{1}$, Mushtaq Talib Hamzah ${ }^{2}$, Hayder Hasan ${ }^{1}$ and Ali Lateef Tarish ${ }^{2}$ \\ k.egab@stu.edu.iq ${ }^{1}$, mushtaq.hamza@stu.edu.iq ${ }^{2}$, hayder.mohammad@stu.edu.iq ${ }^{1}$, aliali@stu.edu.iq ${ }^{2}$ \\ ${ }^{1}$ Electromechanical System Engineering Department, Thi-Qar Technical College, Southern Technical University, \\ Iraq \\ ${ }^{2}$ Thermal Mechanics Engineering. Dept., Eng. Technical College-Basra, Southern Technical University, Iraq
}

\begin{abstract}
The performance of Li-ion batteries is highly dependent on the conditions and temperature distribution inside the battery units. Most of the batteries suffer from high heat dissipation and temperature which influence the battery unit life and efficiency. Therefore, a thermal cooling system is important to regulate the battery unit temperature and reduce the high heat dissipation effect. This study aims to examine the thermal cooling efficiency of a single Li-ion battery unit with a modified heat sink. The study was performed in a laminar flow regime with Reynolds numbers ranging from 20 to 120 . The operating fluid is air and the heat sink is aluminum. The Li-ion battery units' heat sink was adjusted with elliptic holes as perforation located inside the walls of each fin. The elliptic holes are spaced evenly along with the fins with constant size and gap between them. The thermal performance in the battery unit is calculated using the MSMD function which is solved using the Ansys 18.1 software. The results indicate that the maximum battery unit temperature measured in the case is $343.1 \mathrm{~K}$ without a cooling system. The battery unit temperature decreased by $13 \%$ when only air cooling was applied. The use of a heat sink with elliptic perforation plays an important role in lowering the battery unit temperature. The temperature decreased by $21 \%$ compared to the case of without cooling. Furtheremore, analysis of velocity, pressure drop and firiction losses losses were optimized of the heat sink.
\end{abstract}

Keywords: Battery unit, Heat Sink, Perforation, Heat Transfer, Temperature.

\section{Nomenclature}

\begin{tabular}{llcl}
\hline $\mathrm{L}$ & The battery unit length $(\mathrm{mm})$ & Greek & \\
& & symbols & \\
$\mathrm{W}$ & The battery unit width $(\mathrm{mm})$ & $\Delta$ & Difference \\
$\mathrm{L}_{\mathrm{t}}$ & The two tabs Length $(\mathrm{mm})$ & $\rho$ & Air density $\left(\mathrm{kg} / \mathrm{m}^{3}\right)$ \\
$\mathrm{W}_{\mathrm{t}}$ & The two tabs width $(\mathrm{mm})$ & $\mu$ & Air dynamic viscosity $(\mathrm{Pa} \mathrm{s})$ \\
$\mathrm{s}$ & The distance between two tabs $(\mathrm{mm})$ & & \\
$\mathrm{L}_{\mathrm{f}}$ & The fin's hiegtht $(\mathrm{mm})$ & Subscripts & \\
$\mathrm{W}_{\mathrm{f}}$ & The fin's width $(\mathrm{mm})$ & $\mathrm{f}$ & fluid \\
$\mathrm{V}$ & Air velocity $(\mathrm{m} / \mathrm{s})$ & $\mathrm{in}$ & inlet \\
$C_{p, f}$ & Air specific heat $(\mathrm{KJ} / \mathrm{kg} \cdot \mathrm{K})$ & $\mathrm{s}$ & solid \\
$k_{f}$ & Fluid thermal conductivity of the $(\mathrm{W} / \mathrm{m} . \mathrm{K})$ & $(\mathrm{BC})$ & Battery unit \\
$\mathrm{Nu}$ & Nusselt number & $(\mathrm{BC}-\mathrm{A})$ & Battery unit with air cooling \\
$T_{f}$ & Fluid temperature $(\mathrm{K})$ & $(\mathrm{BC}-\mathrm{AH})$ & Battery unit with air heat sink \\
$k_{s}$ & Solid thermal conductivity $(\mathrm{W} / \mathrm{m} . \mathrm{K})$ & $(\mathrm{BC}-\mathrm{AHP})$ & Battery unit with air heat sink \\
& & & and perforation \\
$T_{s}$ & Solid surface temperature $(\mathrm{K})$ & $\mathrm{g}$ & The distance between elliptic \\
& & $\mathrm{a}$ & perforation \\
$\mathrm{P}$ & Air pressure (pa) & $\mathrm{b}$ & Major length of an ellipse \\
$\mathrm{Re}$ & Reynold number & PCM length of an ellipse \\
$D_{h}$ & Hydraulic diameter & Phase change material \\
\hline
\end{tabular}


U Total velocity $(\mathrm{m} / \mathrm{s})$

$q_{\text {eff }}$ Effective heat transfer rate (W)

\section{Introduction}

Li-ion battery units provide clean energy used in electrical generation, transportations, and our life needs due to high energy density. High cell temperature reduces cell performance and is long-lasting. Therefore, a cooling system is important to regulate the cell temperature and prevent the hightemperature effects. The cooling performance of electronic devices, thermal energy, and battery units that generate high heat removal are investigated using air forced convection [1]-[3]. The spacing among the cell is considered to increase the convection heat transfer. The temperature of the cell is decreased by $8 \mathrm{C}$ with an increase in the air velocity. The cooling system using mini-channel and nanofluid is modeled to regulate the battery unit temperature in electric vehicles [4]. The cell temperature with the use of the nanofluid was reduced by $28.65 \%$ in comparison with the battery unit without a cooling system. Cooling of electric battery unit system using PCM with metal foam to obtain acceptable temperature ranges is investigated [5]. Phase change material delay reaching the critical temperature and the metal foam helps distributes the thermal energy in PCM which increase the long life of battery unit. Thermal management cooling using heat pipe in 8-battery unit as a pack delivered 400 watts as energy is investigated [6]. The cooling system can dissipate $50 \mathrm{~W}$ as heat in each cell with maintaining the pack at safe temperature limits. Mini-channel like tree heat sink designs applied to cool Li-ion battery unit at $4 \mathrm{C}$ discharge rate in electric vehicles is investigated [7]. The like tree mini channel better cooling thermal management system than the straight mini channel. The battery unit temperature reduces significantly with an increase in the pressure drop penalty. A comparison of different cooling methods to maintain the temperature at $15^{\circ} \mathrm{C}$ to $35^{\circ} \mathrm{C}$ for a lithium-ion battery unit is achieved [8]. The findings demonstrate that a system of air-cooling requires between 2 and 3 times more energy than other systems, in order to maintain the same temperature in the range of time; an indirect liquid cooling has the highest peak increase of the temperature. The thermal behaviors of $\mathrm{Li}$-ion cells and modules were studied under a range of electrical charges and cooling conditions [9]. Results from the simulation show that the 3D electro-thermal model used for this analysis adequately characterizes the electro-thermal comparability of Li-ion battery units. Heat transfer with phase change materials (PCMs) where the PCM is combined with a Li-ion cell was proposed [10]. The findings show that when PCM can be used, the maximum temperature and temperature escapade in the cell is decreased. The temperature is reduced by $3.0 \mathrm{~K}$ that used a PCM with a thickness of $12 \mathrm{~mm}$. A computational fluid dynamic (CFD) study is proposed to analyze the air cooling mechanism for a 38,120 cell battery unit pack [11]. When the battery unit pack is wide and complete transient simulation is not feasible, the CFD offers a convenient way to measure the battery unit's thermal efficiency. Three-dimensional thermal simulation of a single Li-ion battery unit was discussed [12]. The cell temperature rapidly approaches $40^{\circ} \mathrm{C}$ with low cooling system velocity, and temperature non-uniformity approaches the maximum value of $5{ }^{\circ} \mathrm{C}$ during the $5 \mathrm{C}$ self-discharge condition; but under external short-selling status, temperature increases significantly and reaching nearly the $80{ }^{\circ} \mathrm{C}$ levels, which can cause a temperature increase. The heat sink with diffrernt diffrernt designs has a significant influent on Li-ion battery unit temperature [13]. The heat sink reduced the battery unit temperature while the dimples cause a slightl influence on battery unit temperature. A liquid-cooled rectangular battery unit module concept and experimental constructions are analyzed [14]. At a coolant flow rate of $0.001 \mathrm{Kg} / \mathrm{s}$, the system's thermal resistance was calculated to be less than $0.2 \mathrm{~K} / \mathrm{W}$. The experimental liquid-cooled unit proved to be a feasible alternative for keeping cylindrical $\mathrm{Li}$-ion cells close to their ideal operating temperature. Direct cooling efficiency specifications of Li-ion batteries using dielectric fluid submerged cooling were studied. [15]. The results indicate that a Li-ion pouch cell submerged in the liquid coolant with tab cooling performed better than normal convection at a $3 \mathrm{C}$ discharge rate, with a $46.8 \%$ decrease in the maximum temperature at the critical point.

In this work, an analysis of thermal performance and heat transfer in a single battery unit with a heat sink is investigated. The heat sink was modified using ellipse perforation located in the sidewall of each 
channel. The ellipse perforation has the same size and the gap between them is constant. The study was conducted at different ranges of Reynolds from (20-120) of laminar flow regime. Air is used as a working fluid and heat sink made from aluminum. The determinations of the influence of the heat sink in battery unit temperature, Nusselt number, and friction losses are conducted.

\section{Methodology}

\subsection{Physical Model}

The battery unit schematic design is illustrated in Figure 1. The unit of $60 \mathrm{~mm}$ length and $40 \mathrm{~mm}$ width was considered. The positive and negative tab lengths and widths $\left(\mathrm{L}_{t} * \mathrm{~W}_{\mathrm{t}}\right)$ are $(12.5 * 10) \mathrm{mm}$ and the gap length between them is $10 \mathrm{~mm}$. The cell and tabs have the same thickness of $2 \mathrm{~mm}$. The cell is made from Lithium and the battery unit tabs are made from Nickel. The battery unit generates heat to the atmosphere as heat flux of $100 \mathrm{~W}$ through all battery unit directions during its operation. The heat transfer through the cell is conduction while the heat transfer by convection in the case of the cooling system. The heat sink size is $\mathrm{H} \times \mathrm{W}=100 \mathrm{~mm} \times 100 \mathrm{~mm}$. The fins' height and width are $(3 * 2) \mathrm{mm}$ which are located along with the battery unit. The heat sink is made from pure aluminum that is assumed to have constant thermal properties. The working fluid is air, which the thermal properties of air are calculated at an average temperature. The heat sink is placed at the two large sides of the battery unit to dissipate more heat through discharging. The heat sink with perforation is conducted using elliptic holes through the sidewalls of the heat sink. The elliptic holes are distributed horizontally along with the fins with a constant gap among them. The case of the only battery unit is named $\mathrm{BC}$, the case of battery unit with cooling called BC-A, the case of using battery unit with heat sink is (BC-AH), and the last case of using battery unit with heat sink with perforation which called BC-AHP. For more details, the modified heat sink with perforation of battery unit with cooling case (BC-AHP) is shown in Figure 2.

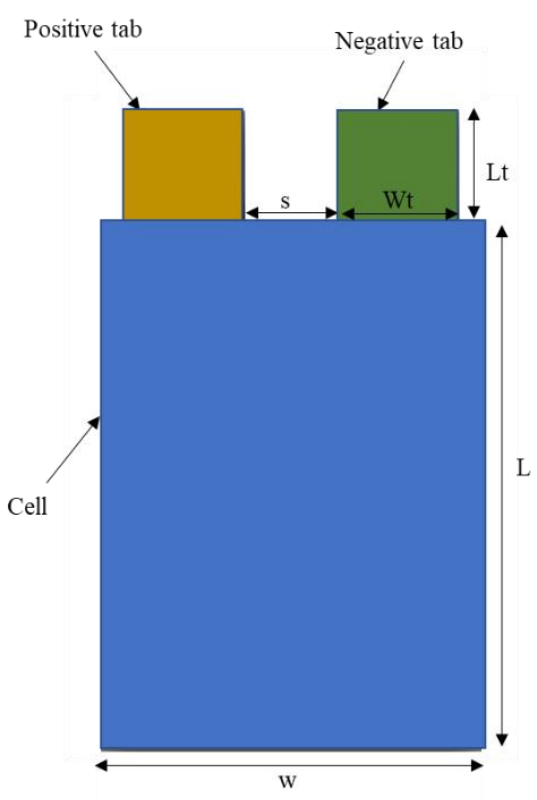

(b)

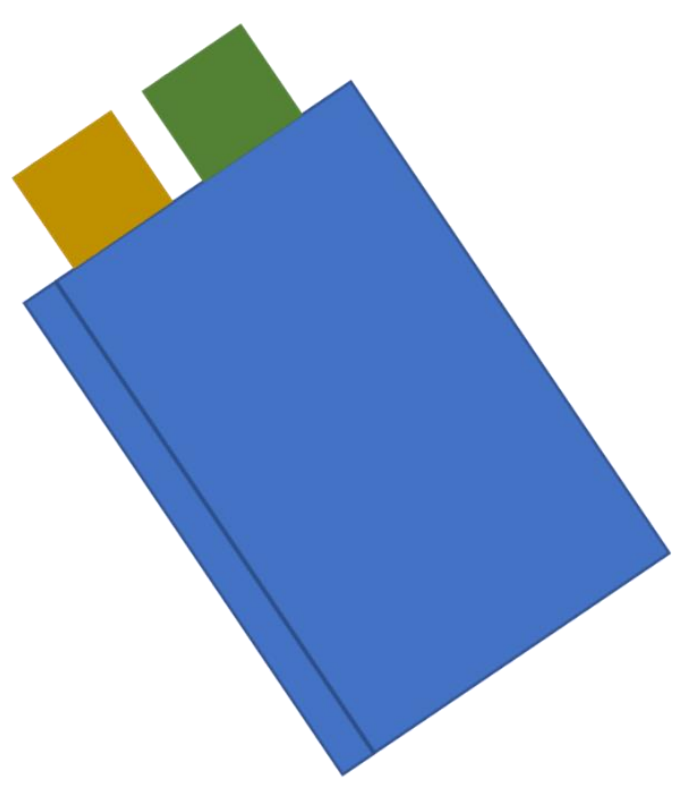

Fig. 1 (a) The the battery unit schematic design (b) The 3-D view of battery unit. 


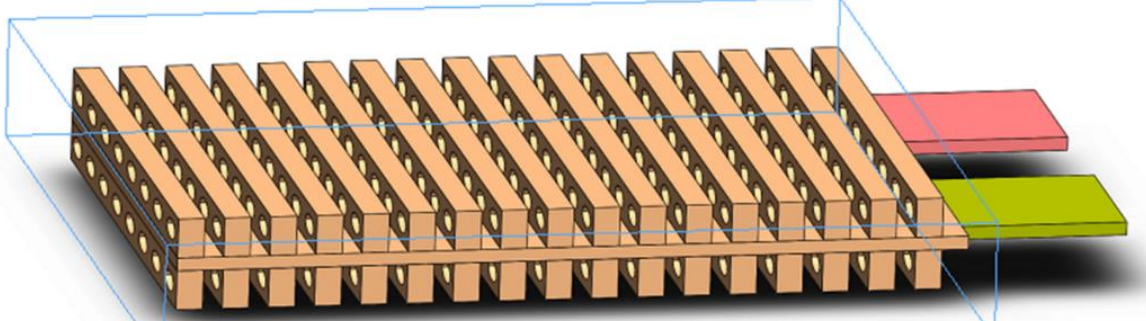

(b)

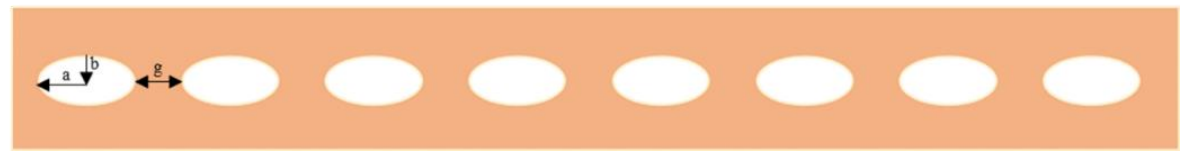

Fig. 2 The modified heat sink with perforation of (a) Cooling system of battery unit in case of (BCAHP) (b) perforated elliptic heat sink design.

\subsection{Governing Equations and Boundary Conditions}

To evaluate the heat transfer and fluid flow in heat sink bounded the battery unit, solution of the governing equations of continuity, momentum, and energy equations should be performed as:

Continuity equation:

$\frac{\partial u}{\partial x}+\frac{\partial v}{\partial y}+\frac{\partial w}{\partial z}=0$

Momentum equation:

$\rho_{f}(\vec{U} \cdot \nabla \vec{U})=-\nabla P+\nabla \cdot\left(\mu_{f} \nabla \vec{U}\right)$

Energy equation:

$$
\rho_{f} C_{p, f}\left(\vec{U} \cdot \nabla T_{f}\right)=\nabla \cdot\left(k_{f} \nabla T_{f}\right)
$$

Where $\vec{U}, \mathrm{P}, \mathrm{T}_{\mathrm{f}}, \rho, C_{p}, \mu$ and $k$ are velocity, pressure, temperature, specific heat, viscosity, and thermal conductivity. The subscripts $f$ and s refer to fluid and solid respectively. The calculations of thermal load in battery unit heat sink were found numerically but the parameters like Reynold and Nusselt number were obtained from the below correlations. The hydraulic diameter of the channel is defined as:

$$
D_{h}=\frac{4\left(W_{l} * H_{f}\right)}{2\left(W_{l}+H_{f}\right)}
$$

The Reynolds number can be defined as:

$$
R_{e}=\frac{\rho_{f} u_{i} D_{h}}{\mu_{f}}
$$

The overall heat transfer coefficient is [16] as:

$$
h=\frac{Q_{e f}^{\prime \prime}}{\left(T_{w}-T_{f}\right)}
$$

The Nusselt number is: 


$$
N_{u}=\frac{h D_{h}}{k_{f}}
$$

The friction loss is:

$$
f=\frac{2 \Delta P D_{h}}{\rho_{f} L u_{m}^{2}}
$$

Uniform boundary conditions are asumed in the battery unit and heat sink and constant temperature. The boundary conditions in the battery unit heat sink are explained in Table 1. Air was used as working fluid while the heat sink was made from aluminum. The flow was laminar and variable air velocity ranging (10.-0.5) $\mathrm{mm}$ were applied. The constant thermal conductivity and dynamic viscosity are considered.

Table 2 shows the of properties of Li-ion battery unit.

\begin{tabular}{|c|c|c|}
\hline Zone & Boundary conditions & Expression \\
\hline Inlet & Velocity-inlet & $\mathrm{y}=0, \mathrm{u}=\mathrm{u}_{\text {in, }} \mathrm{u}_{\text {in }}=(0.1-0.5) \mathrm{m} / \mathrm{s}, \mathrm{T}_{\text {in }}=300 \mathrm{~K}$ \\
\hline Outlet & Pressure outlet & $\mathrm{y}=\mathrm{L}, \mathrm{P}_{\mathrm{f}}=\mathrm{P}_{\mathrm{out}}=0($ gauge pressure $)$ \\
\hline $\begin{array}{l}\text { Top and Bottom } \\
\text { walls }\end{array}$ & Constant heat flux & $\mathrm{x}=0,-\mathrm{k}_{\mathrm{s}} \frac{\partial \mathrm{T}_{\mathrm{s}}}{\partial \mathrm{y}}=\mathrm{q}=100 \mathrm{~W}$ \\
\hline $\begin{array}{l}\text { Left and right } \\
\text { walls }\end{array}$ & Symmetry & $\frac{\partial \mathrm{T}_{\mathrm{s}}}{\partial \mathrm{y}}=0$ \\
\hline $\begin{array}{l}\text { Inner walls } \\
\text { Other walls }\end{array}$ & $\begin{array}{l}\text { No slip } \\
\text { Adiabatic }\end{array}$ & $\begin{array}{l}\mathrm{u}=\mathrm{v}=\mathrm{w}=0 \\
\frac{\partial \mathrm{T}_{\mathrm{s}}}{\partial \mathrm{y}}=0=\frac{\partial \mathrm{T}_{\mathrm{f}}}{\partial \mathrm{y}}\end{array}$ \\
\hline
\end{tabular}

Table 1 The boundary conditions.

Table 2 The battery unit, aluminum, and air properties.

\begin{tabular}{lllll}
\hline Material & \multicolumn{1}{c}{$\boldsymbol{\rho}$} & \multicolumn{1}{c}{$\boldsymbol{c}_{\boldsymbol{p}}$} & \multicolumn{1}{c}{$\mathbf{k}$} & \multicolumn{1}{c}{$\boldsymbol{\mu}$} \\
\hline Aluminum & 2719 & 871 & 202.4 & - \\
Air & 1.242 & 4181 & 0.0242 & 0.00000176 \\
Positive tab & 2100 & 800 & 1 & - \\
Negative tab & 1400 & 800 & 1.48 & - \\
cell & 1299 & 1978 & 18.1 & - \\
\hline
\end{tabular}

\subsection{Numerical Solution}

The generated heat in the battery unit is obtained using the MSMD function which is solved using finite volume method Ansys software. The physical properties of the battery unit and tabs are assumed to be constant. The governing equations of continuity, momentum, and energy were solved. The battery unit geometry and heat sink were modeled using Solidwork 2013. In this work, the SIMPLEC algorithm was used for calculations of velocity, temperature, and pressure drop, and a second upwind scheme was applied. The residual results for continuity, momentum, and energy equations are set to be less than $10^{-}$ ${ }^{6}, 10^{-6}, 10^{-9}$ respectively to get a suitable converging for Navier-stokes equations.

\subsection{Mesh Independence Study}

The importance of obtaining reliable solution results depends mainly on the study of mesh independence. To perform a mesh independence study, the finer mesh was applied to all systems with considering the mesh of elliptic perforation in this study. The perforation is modeled using finer mesh than fined heat sink and battery unit. The battery unit temperature with finned heat sink case (Li-AH) for various mesh sizes at a constant air velocity of $0.1 \mathrm{~m} / \mathrm{s}$ is considered. The mesh sizes of $(1104531,1150345,1240387$, 1289301and1357123) are tested to optimize the best mesh size that does not affect the solution results. The mesh size of 1357123 provides fair temperature results which can be carried out in the present study. Figure 3 shows the mesh of the battery unit with the cooling system of the heat sink and elliptic perforation case (BC-AH). 


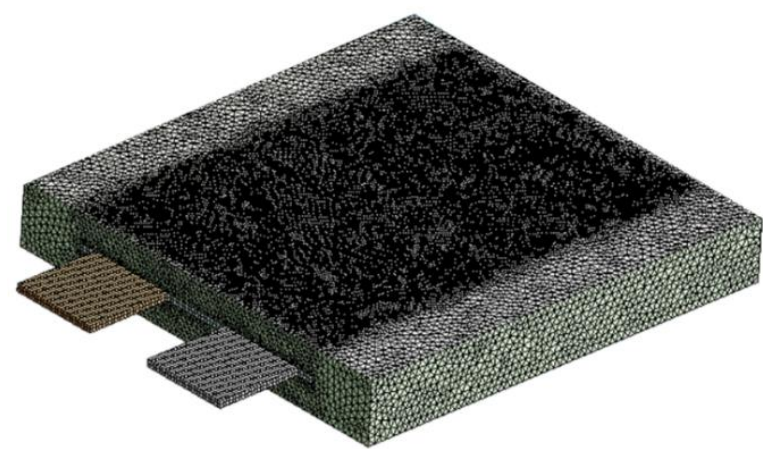

Fig. 3 Mesh of cooling system in the battery unit including the heat sink and elliptic perforation case (BC-AH).

\section{Model Validation}

To validate the model results, geometry, boundary conditions, and different discharge rate of single battery units are similar to the study in [17]. The influence of discharge rates on battery unit temperature is shown in Figure 4. Increase the discharge rate increases the heat dissipation which increases the battery unit temperature. A good agreement between the model results and the results of [17] with a $2 \%$ error. Therefore, the numerical model is accurate and can perform investigations of the effect of cooling systems on battery unit temperature distributions.

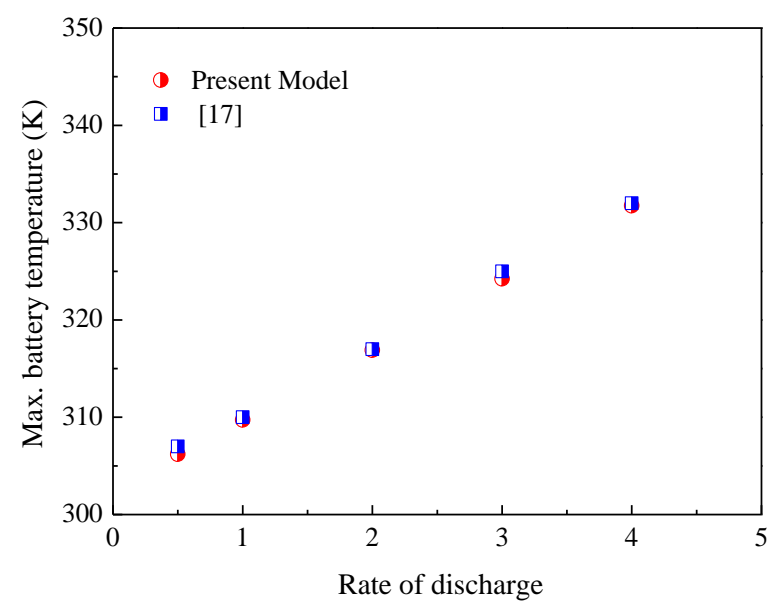

Fig. 4 The influence of discharge rates on battery unit temperature.

\section{Results and Discussions}

The heat sink and elliptic perforated design cooling performance were evaluated with regards to battery unit heat generation, temperature, and thermal performance criteria. This analysis was conducted by study the influence of the cooling system on battery unit temperature distributions and characteristics of velocity, pressure drop, and friction losses. The optimization to find the best thermal performance criteria is achieved.

\subsection{Characteristics of Thermal Distributions}

To evaluate the influence of applying heat sink and perforation for the battery unit cooling, four configurations of the only battery unit (BC), battery unit with air cooling (BC-A), battery unit with air heat sink (BC-AH), and battery unit with an elliptic air heat sink and perforation (BC-AHP) were performed. The perforation was applied at the sidewalls of fins with constant areas of the ellipse. The gap between the perforation is kept constant. The battery unit generates the same heat flux in all cases 
and the same boundary conditions in the heat sink applied to other case studies. The study was considered at ranges of Reynolds number of (200-1200) to ensure laminar flow. The temperature distributions in the battery unit with different cooling configurations are shown in Figure 5 at Reynolds number 30. The maximum battery unit temperature is $343.1 \mathrm{~K}$ in a single battery unit without a cooling case (BC). With applying air cooling case (BC-A), the battery unit temperature reduced by $13 \%$ which shows how significant the air cooling affects maximum battery unit temperature. The heat sink plays an important role in reducing the battery unit temperature as in the case (BC-AH) where the battery unit temperature decreased by $21 \%$ compared to only battery units without cooling. The perforation increases the convection heat transfer area and causes a change in airflow behavior through the channels. The battery unit temperature using a perforation heat sink case (BC-AHP) was reduced by $28 \%$. The battery unit temperature reduced with an increase in the Reynolds number values. Figure 6 shows the battery unit temperature at different Reynolds numbers. The heat dissipation increases with increase the values of Re which leads decrease battery unit temperatures. In the perforation heat sink, the lowest battery unit temperature is noticed because of the flow disturbance and circulation inside the perforated areas. The Nusselt number calculation in all cases is shown in Figure $\mathbf{7}$ at various Reynolds number values. The Nusselt number increases with the increase in the value of the Reynolds number. The Nusselt number in case (BC-AHP) is the best because of the highest momentum forces due to increasing air velocity. The Nusselt number is 30\% and 20\% higher compared to case (BC-A) and (BC-AH) respectively. It is noticed that how perforation enhances the heat transfer in the heat sink which reduced the battery unit temperature.
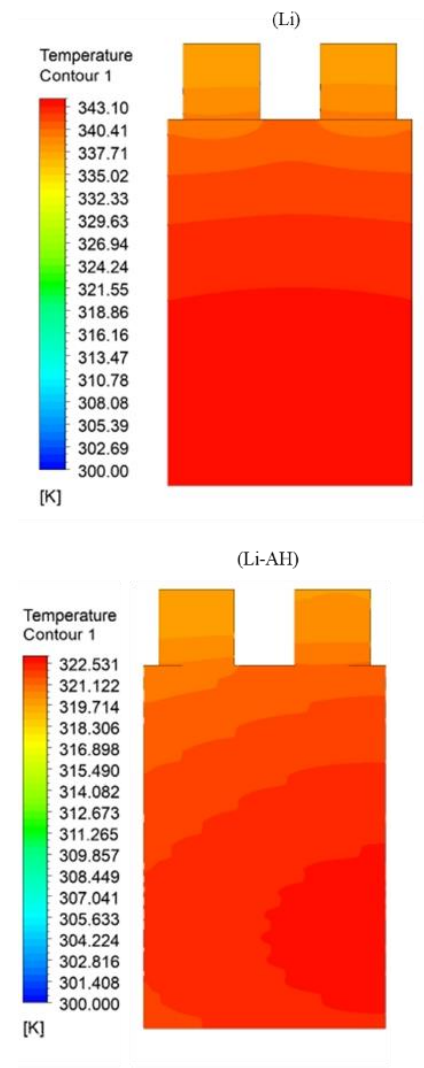

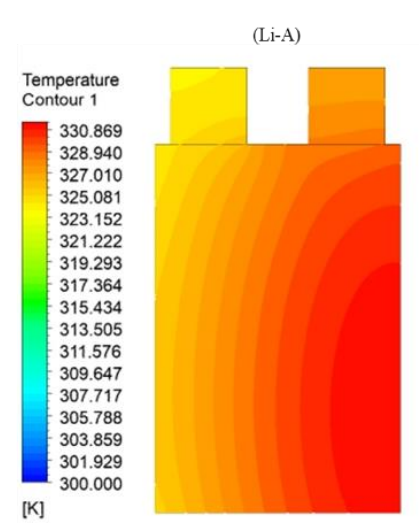

$[\mathrm{K}]$

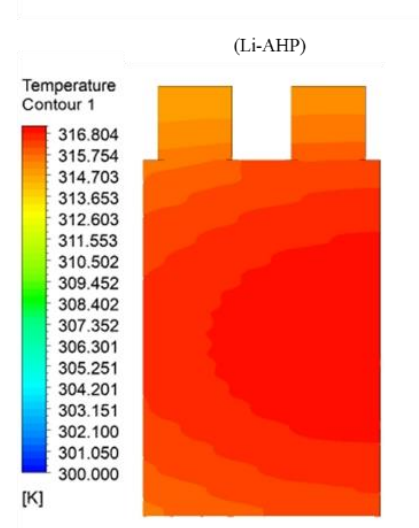

Fig. 5 The temperature distributions in the battery unit with different cooling configurations. 


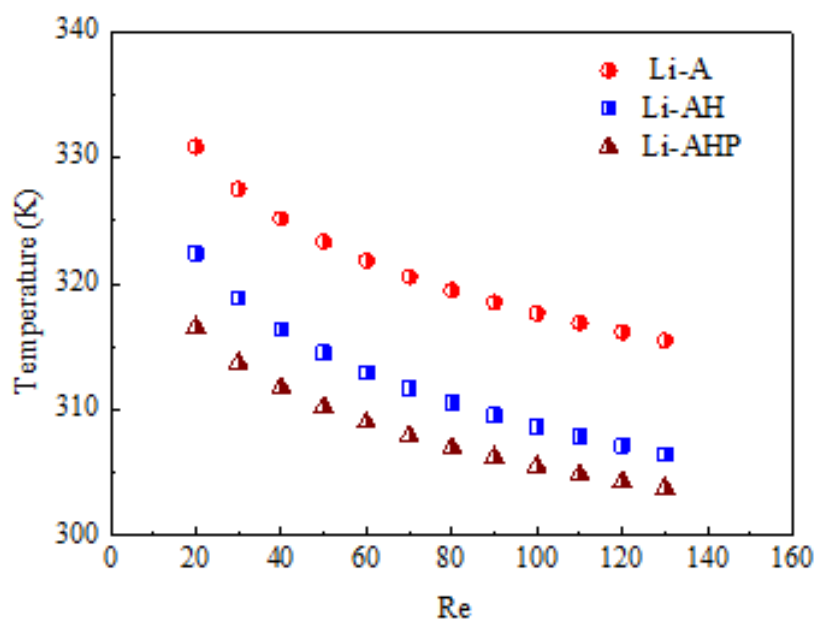

Fig. 6 The battery unit temperature at different Reynolds numbers.

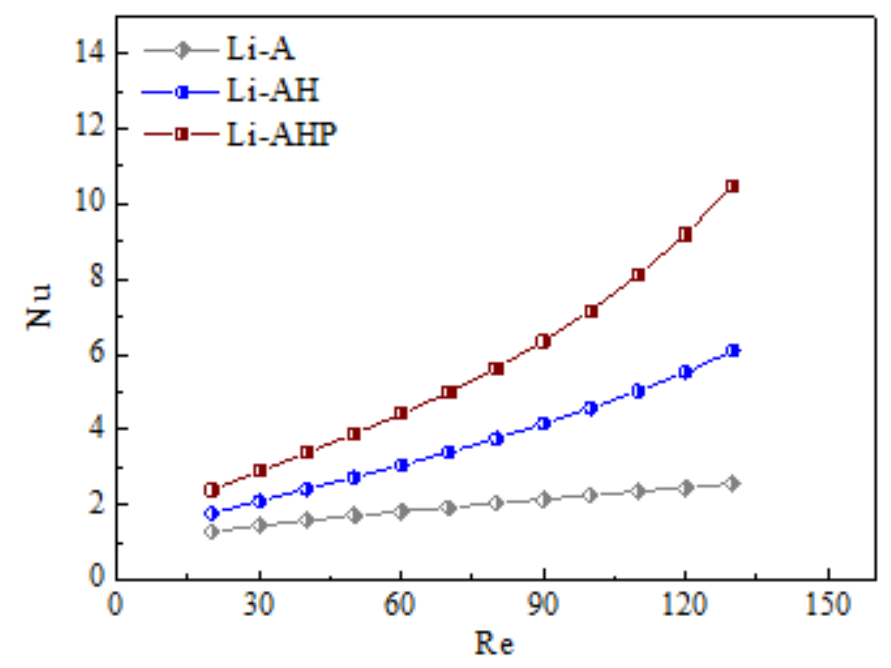

Fig. 7 Nusselt number value in all cases.

\subsection{Characteristics of Velocity, Pressure, and Friction Losses}

The hydrodynamic characteristics in heat sink battery units are investigated due to the importance of fluid flow behavior's effect on thermal performance. Therefore, the velocity distribution of the cooling system in the battery unit is investigated in the case of (BC-A), (BC-AH), and (BC-AHP). The contour of velocity distributions is shown in Figure 8 at Reynolds number is 20 and $\mathrm{z}=2.5 \mathrm{~mm}$. The perforations in the case of (BC-AHP) have a significant influence on flow velocity since they cause small mixing and disturbance compared to the flow in the case of (BC-AH). The high velocity reduces the effect of thermal boundary layers and enhances the heat transfer performance. However, high-pressure penalty and friction losses increase in the case of (BC-AHP) compared to other cases. Figure 9 shows the pressure penalty in cases of (BC-A), (BC-AH), and (BC-AHP) in the $\mathrm{x}-\mathrm{y}$ plane at $\mathrm{z}=2.5 \mathrm{~mm}$ and Reynold number of 20. Linear reduce in pressure losses in case of battery unit with air (BC-A) along the channel. However, further increase in pressure losses in perforation with heat sink due to the inducing flow circulation and interruption at the locations of perforation existing. The pressure drops in the case of (BC-AHP) increased by 3 times compared to $(\mathrm{BC}-\mathrm{AH})$. Therefore, the heat sink with perforation enhances the thermal performance, but it increases the pressure losses.

Figure 10 shows the friction losses in the battery unit heat sink cases at ranges of Reynolds number (20120). The heat sink with perforation (BC-AHP) has the highest friction losses compared to other cases at all ranges of RE. The friction losses in case (BC-AHP) are 3 times higher than in case (BC-AH) which 
means the viscous forces become dominant in the heat sink with perforation. In the case of (BC-AH) and (BC-A), the friction losses reduce slowly at different ranges of Re but the friction losses decrease becomes faster in the case of (BC-AHP).
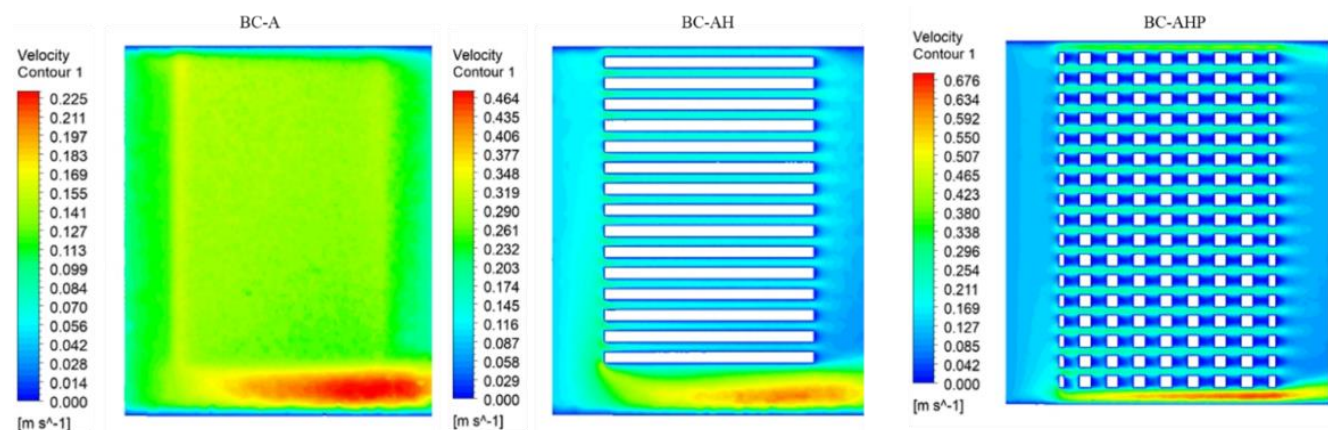

Fig. 8 Contour of velocity distributions in cases of (BC-A), (BC-AH), and (BC-AHP) in the $x-y$ plane at $\mathrm{z}=2.5 \mathrm{~mm}$ and Reynold number of 20 .
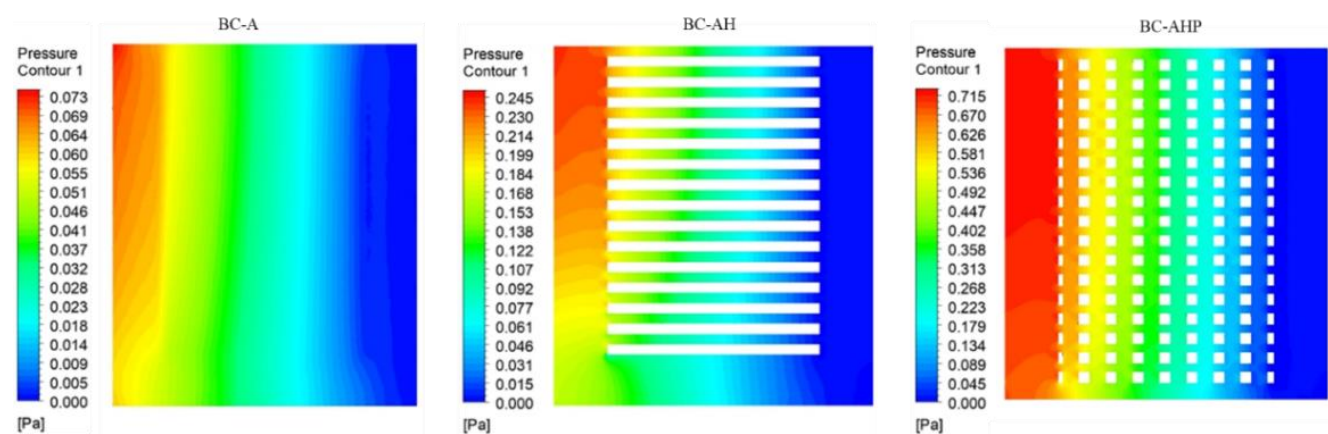

Fig. 9 The pressure penalty in cases of (BC-A), $(\mathrm{BC}-\mathrm{AH})$, and $(\mathrm{BC}-\mathrm{AHP})$ in the $\mathrm{x}-\mathrm{y}$ plane at $\mathrm{z}=2.5 \mathrm{~mm}$ and Reynold number of 20.

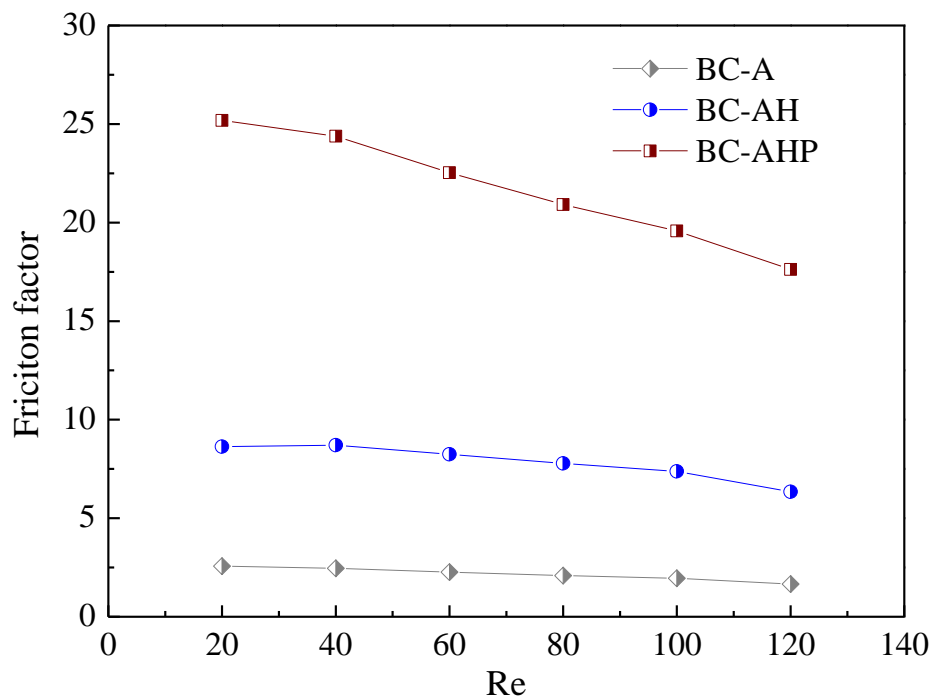

Fig. 10 The friction losses in the battery unit heat sink cases at Re ranges (20-120). 


\section{Conclusions}

Thermal cooling analysis with use of elliptic heat sink and perforation is performed on a single Li-ion battery unit. The key aim of using the single Li-ion battery unit for cooling with an elliptical perforated thermal sink minimizes heat and keeps the temperature steady. The induced heat in the battery unit is calculated with the MSMD variable, which is solved with the Ansys software using the finite volume procedure. The battery unit's and tabs' physical properties are considered to be unchanged. In both cases, the battery unit produces the same heat flux and the heat sink has the same boundary conditions as in the other case studies. To ensure laminar flow, the analysis was conducted at Reynolds number ranges of (200-1200). In the case of a power outage, the maximum battery unit temperature is $343.1 \mathrm{~K}$. (BC). The battery unit temperature dropped by $13 \%$ when the case (BC-A) was used, demonstrating how important air cooling is for optimum battery unit temperature. The perforation enhances the diffusion distance for convection heat transfer and alters the airflow behavior across the channels. The temperature of the battery unit with the case (BC-AHP) was decreased by $28 \%$. In both cases, the battery unit temperatures decreased as the Reynolds number increased, due to increased air velocity, which improved heat removal. Because of the highest momentum forces due to increased air velocity, the Nusselt number in case (BCAHP) is the best. In comparison to cases (BC-A) and (BC-AH), the Nusselt number is $30 \%$ and $20 \%$ higher, respectively. In the case of (BC-AHP), however, the high-pressure penalty and friction losses are greater than in other cases. In the case of (BC-AHP), the pressure reduction was three times higher than in the case of (BC-AHP) (BC-AH). As a result, although the heat sink with perforation improves thermal efficiency, it also increases pressure losses.

\section{References}

[1] R. D. Jilte and R. Kumar, "Numerical investigation on cooling performance of Li-ion battery unit thermal management system at high galvanostatic discharge," Eng. Sci. Technol. an Int. J., vol. 21, no. 5, pp. 957-969, 2018.

[2] S. K. Oudah, R. Fang, A. Tikadar, K. Egab, C. Li, and J. A. Khan, "The effects of hybrid sandblasting patterns on the heat transfer performance in a single-phase microchannel heat sink," in ASME International Mechanical Engineering Congress and Exposition, Proceedings (IMECE), 2017, vol. 8.

[3] K. Egab, A. Okab, H. S. Dywan, and S. K. Oudah, "Enhancing a solar panel cooling system using an air heat sink with different fin configurations," in IOP Conference Series: Materials Science and Engineering, 2020, vol. 671, no. 1.

[4] S. Wiriyasart, C. Hommalee, S. Sirikasemsuk, R. Prurapark, and P. Naphon, "Thermal management system with nanofluids for electric vehicle battery unit cooling modules," Case Stud. Therm. Eng., vol. 18, no. December 2019, p. 100583, 2020.

[5] B. Buonomo, "Thermal cooling behaviors of lithium-ion batteries by metal foam with phase change materials," Energy Procedia, vol. 148, pp. 1175-1182, 2018.

[6] J. Smith, R. Singh, M. Hinterberger, and M. Mochizuki, "thermal management system for electric vehicle using heat pipes,” Int. J. Therm. Sci., vol. 134, no. June 2017, pp. 517-529, 2018.

[7] H. ling Liu, H. bo Shi, H. Shen, and G. Xie, "The performance management of a Li-ion battery unit by using tree-like mini-channel heat sinks: Experimental and numerical optimization," Energy, vol. 189, p. 116150, 2019.

[8] D. Chen, J. Jiang, G. H. Kim, C. Yang, and A. Pesaran, "Comparison of different cooling methods for lithium ion battery units,” Appl. Therm. Eng., vol. 94, pp. 846-854, 2016.

[9] K. Yeow, H. Teng, M. Thelliez, and E. Tan, "3D Thermal Analysis of Li-ion Battery units with Various Geometries and Cooling Conditions Using Abaqus," Imechanica.Org, no. Figure 1, pp. 1-17, 2012.

[10] N. Javani, I. Dincer, G. F. Naterer, and B. S. Yilbas, "Heat transfer and thermal management with PCMs in a Li-ion battery unit for electric vehicles," International Journal of Heat and Mass Transfer, vol. 72, pp. 690-703, 2014.

[11] L. H. Saw, Y. Ye, A. A. O. Tay, W. T. Chong, S. H. Kuan, and M. C. Yew, "Computational fluid dynamic and thermal analysis of Lithium-ion battery unit pack with air cooling," Appl. Energy, vol. 177, pp. 783-792, 2016.

[12] Y. Li, Z. Zhou, and W. T. Wu, "Three-dimensional thermal modeling of Li-ion battery unit and 50 V Li-ion battery unit pack cooled by mini-channel cold plate," Appl. Therm. Eng., vol. 147, pp. 829-840, 2019.

[13] K. Egab and S. K. Oudah, "Thermal management analysis of li-ion battery unit-based on 
cooling system using dimples with air fins and perforated fins," Int. J. Therm. Sci., vol. 171, no. July 2021, p. 107200, 2022.

[14] D. M. Arun, D. Hamilton, M. N. Krishna, and M. Minakshi, "Design, Development and Thermal Analysis of and Stationary Applications," energies, vol. 13, 2020.

[15] M. Suresh Patil, J. H. Seo, and M. Y. Lee, "A novel dielectric fluid immersion cooling technology for Li-ion battery unit thermal management," Energy Convers. Manag., vol. 229, no. September 2020, p. 113715, 2021.

[16] M. I. Hasan, "Investigation of flow and heat transfer characteristics in micro pin fin heat sink with nanofluid," Appl. Therm. Eng., vol. 63, no. 2, pp. 598-607, 2014.

[17] Y. S. Ranjbaran, M. H. Shojaeefard, and G. R. Molaeimanesh, "Thermal behavior of a commercial prismatic Lithium-ion battery unit applied in electric vehicles," Int. J. Automot. Eng. Veh., vol. 8, no. 2, pp. 2700-2708, 2018. 